\title{
Anammox Bacteria Are Potentially Involved in Anaerobic Ammonium Oxidation Coupled to Iron(III) Reduction in the Wastewater Treatment System
}

OPEN ACCESS

Edited by:

Lei Yan,

Heilongjiang Bayi Agricultural

University, China

Reviewed by:

Nan Li,

Tianjin University, China

Kevin Thomas Finneran,

Clemson University, United States

${ }^{*}$ Correspondence:

Guo-Wei Zhou

gwzhou@ahu.edu.cn

Specialty section:

This article was submitted to

Microbiological Chemistry

and Geomicrobiology,

a section of the journal

Frontiers in Microbiology

Received: 30 May 2021

Accepted: 04 August 2021

Published: 10 September 2021

Citation:

Yang X-R, Li H, SU J-Q and Zhou G-W (2021) Anammox Bacteria Are Potentially Involved in Anaerobic

Ammonium Oxidation Coupled to Iron(III) Reduction

in the Wastewater Treatment System.

Front. Microbiol. 12:717249.

doi: 10.3389/fmicb.2021.717249

\begin{abstract}
Xiao-Ru Yang ${ }^{1,2}$, Hu Li 1,2, Jian-Qiang Su ${ }^{1,2}$ and Guo-Wei Zhou ${ }^{1,2,3 *}$
${ }^{1}$ Key Lab of Urban Environment and Health, Institute of Urban Environment, Chinese Academy of Sciences (CAS), Xiamen, China, ${ }^{2}$ Center for Excellence in Regional Atmospheric Environment, Institute of Urban Environment, Chinese Academy of Sciences (CAS), Xiamen, China, ${ }^{3}$ School of Resources and Environmental Engineering, Anhui University, Hefei, China
\end{abstract}

Anaerobic ammonium oxidation coupled to nitrite reduction (termed as Anammox) was demonstrated as an efficient pathway to remove nitrogen from a wastewater treatment system. Recently, anaerobic ammonium oxidation was also identified to be linked to iron(III) reduction (termed Feammox) with dinitrogen, nitrite, or nitrate as end-product, reporting to enhance nitrogen removal from the wastewater treatment system. However, little is known about the role of Anammox bacteria in the Feammox process. Here, slurry from wastewater reactor amended with ferrihydrite was employed to investigate activity of Anammox bacteria in the Feammox process using the ${ }^{15} \mathrm{~N}$ isotopic tracing technique combined with $16 \mathrm{~S}$ rRNA gene amplicon sequencing. A significantly positive relationship between rates of ${ }^{15} \mathrm{~N}_{2}$ production and iron(III) reduction indicated the occurrence of Feammox during incubation. Relative abundances of Anammox bacteria including Brocadia, Kuenenia, Jettenia, and unclassified Brocadiaceae were detected with low relative abundances, whereas Geobacteraceae dominated in the treatment throughout the incubation. ${ }^{15} \mathrm{~N}_{2}$ production rates significantly positively correlated with relative abundances of Geobacter, unclassified Geobacteraceae, and Anammox bacteria, revealing their contribution to nitrogen generation via Feammox. Overall, these findings suggested Anammox bacteria or cooperation between Anammox bacteria and iron(III) reducers serves a potential role in Feammox process.

Keywords: Feammox, Anammox bacteria, ammonium oxidation, iron(III) reduction, ${ }^{15} \mathrm{~N}_{2}$ production

\section{INTRODUCTION}

Feammox [anaerobic ammonium oxidation coupled to iron(III) reduction] is a pathway of nitrogen cycling identified recently and makes a contribution to nitrogen loss in various environments, such as terrestrial (e.g., wetland, tropical rainforest, and paddy soils) and aquatic ecosystem (e.g., freshwater and marine) in addition to denitrification, co-denitrification, and anaerobic ammonium oxidation (Clement et al., 2005; Yang et al., 2012; Ding et al., 2014, 2017, 2019; Huang and Jaffé, 2014; Zhou et al., 2016). Previous studies showed that iron(III)-reducing bacteria such as Anaeromyxobacter, Pseudomonas, Geobacter, Desulfosporosinus, Dechloromonas, 
and Geothrix always dominated in the Feammox "pool" (Zhou et al., 2016; Li et al., 2019); however, these iron(III) reducers prefer to utilize organic carbon for iron(III) reduction. Only a minor part of iron(III) reduction $(0.4-6.1 \%)$ by these bacteria is estimated to be associated with Feammox in the natural or artificial environments (Yang et al., 2012; Ding et al., 2014, 2017, 2019; Li et al., 2015; Zhou et al., 2016). As a replacement, ${ }^{15} \mathrm{NH}_{4}{ }^{+}$is generally employed to trace the occurrence of Feammox; however, it is hard to directly identify the Feammox microbes through DNA or RNA stable isotope probing because the Feammox process results in conversion of ${ }^{15} \mathrm{NH}_{4}{ }^{+}$to ${ }^{15} \mathrm{~N}_{2} /{ }^{15} \mathrm{NO}_{3}{ }^{-} /{ }^{15} \mathrm{NO}_{2}{ }^{-}$but not assimilation of ${ }^{15} \mathrm{NH}_{4}{ }^{+}$into DNA and RNA. As a result, "Feammox microbes" are difficult to be directly captured from the incubation.

Sawayama (2006) has reported that the possibility of Feammox happened in a wastewater treatment system, which is recently expected to become another important way to remove nitrogen from the sludge of wastewater in addition to Anammox. Anammox is another anaerobic ammonium oxidation pathway that used nitrite as an electron acceptor with forming dinitrogen (Rikmann et al., 2014). Furthermore, the addition of iron(III) oxides is indicated to increase the efficiency of nitrogen removal in the system (Chen et al., 2014; Wang et al., 2016; Li H. et al., 2018; Yin et al., 2019). These discoveries further suggest the occurrence of Feammox in the Anammox-based nitrogen removal system of a wastewater treatment reactor. However, the Feammoxinvolving microorganisms in the wastewater treatment system is still under-characterized. Anammox bacteria, including members of the Planctomycetales such as Brocadia, Kuenenia, Anammoxoglobus, Jettenia, Anammoximicrobium moscowii, and Scalindua (Rikmann et al., 2014), possesses a versatile metabolism involved in the utilization of diverse electron donors (e.g., $\mathrm{NH}_{4}{ }^{+}$ and propionate) and acceptors (e.g., $\mathrm{NO}_{2}{ }^{-}, \mathrm{NO}_{3}{ }^{-}$, and $\mathrm{SO}_{4}{ }^{2-}$ ) (Strous et al., 2002; Cervantes et al., 2009; Rikmann et al., 2014; Rios-Del Toro and Cervantes, 2016; Rios-Del Toro et al., 2018). Inspired by these recent findings, we hypothesized that $\mathrm{Fe}$ (III) can play as terminal electron acceptors in anaerobic ammonium oxidation mediated by Anammox bacteria in the sludge from a wastewater treatment reactor.

In order to verify our hypothesis, sludge from a wastewater treatment reactor, which has been demonstrated to employ the Anammox process to remove nitrogen (Zhang et al., 2012), was used in this study. Through the ${ }^{15} \mathrm{NH}_{4}{ }^{+}$-based isotopic tracing technique with $16 \mathrm{~S}$ rRNA gene Illumina sequencing, we amended the sludge with ferrihydrite to investigate whether (1) Feammox occurred in the Anammox enrichment and (2) the Anammox organisms were involved in Feammox process.

\section{MATERIALS AND METHODS}

\section{Experimental Procedures}

The sludge was obtained from a wastewater treatment reactor (Zhang et al., 2012). The dominant electron donor and acceptor were $\mathrm{NH}_{4}{ }^{+}$and $\mathrm{NO}_{2}{ }^{-}$in the wastewater treatment reactor, respectively, which has been established as a stable, completely autotrophic nitrogen removal process over nitrite (Canon). Theoretically, the Canon is a process combining partial nitrification with Anammox within a single reactor, which has been shown to be a cost-efficient autotrophic process for nitrogen removal, as it has no need for a carbon source and has low requirement for oxygen (Zhang et al., 2012). The characteristic of the sludge is detailed in Supplementary Table 1. The Feammox experiment was initiated by inoculating $10 \%(\mathrm{v} / \mathrm{v})$ sludge into $20 \mathrm{ml}$ basal medium and incubated at $30^{\circ} \mathrm{C}$ in the dark. The basal medium ( $\mathrm{pH} 6.8-7.2)$ consists of $\mathrm{MgCl}_{2} \cdot 6 \mathrm{H}_{2} \mathrm{O}\left(0.4 \mathrm{~g} \mathrm{~L}^{-1}\right)$, $\mathrm{CaCl}_{2} \cdot \mathrm{H}_{2} \mathrm{O}\left(0.1 \mathrm{~g} \mathrm{~L}{ }^{-1}\right),{ }^{14} \mathrm{NH}_{4} \mathrm{Cl}\left(0.027 \mathrm{~g} \mathrm{~L}^{-1}\right), \mathrm{KH}_{2} \mathrm{PO}_{4}$ (0.6 $\left.\mathrm{g} \mathrm{L}^{-1}\right), 1 \mathrm{ml} \mathrm{L}^{-1}$ vitamin solution (Lovley and Phillips, 1988), $1 \mathrm{ml} \mathrm{L}^{-1}$ trace element solution (Lovley and Phillips, 1988), $30 \mathrm{mmol} \mathrm{L}^{-1}$ bicarbonate buffer, and $4 \mathrm{mmol} \mathrm{L}^{-1} \mathrm{Fe}(\mathrm{III})$. The headspace of the serum vials was flushed with ultrapure helium. Ferrihydrite was synthesized as previously described (Kappler et al., 2014) and used as the Fe(III) source. The basal medium and ferrihydrite were autoclaved $\left(120^{\circ} \mathrm{C}\right.$ for $\left.20 \mathrm{~min}\right)$ before use, and the vitamin solution and trace element solution were filtrated with a $0.22-\mu \mathrm{m}$ filter from the stock solutions. In order to enrich the Feammox-associated microbial population, the cultures were anaerobically transferred $(10 \%, \mathrm{v} / \mathrm{v})$ to fresh medium for three generations once the $\mathrm{Fe}(\mathrm{III})$ was used up.

For the labeled experiment, ${ }^{14} \mathrm{NH}_{4} \mathrm{Cl}$ was replaced by ${ }^{15} \mathrm{NH}_{4} \mathrm{Cl} \quad\left({ }^{15} \mathrm{~N}, \quad 99.14 \%\right.$; Cambridge Isotope Laboratories, Andover, MA, United States) to prepare the fresh medium. In brief, aliquots $(2 \mathrm{ml})$ of the Feammox enrichment were centrifuged and washed three times with sterile deionized water before inoculating into the $20 \mathrm{ml}$ of fresh ${ }^{15} \mathrm{NH}_{4} \mathrm{Cl}$-labeled medium. Three treatments were set up: (1) $\mathrm{NH}_{4}{ }^{+}$: Feammox enrichment was inoculated in the $20 \mathrm{ml}$ of ${ }^{15} \mathrm{NH}_{4} \mathrm{Cl}$-added basal medium amended without ferrihydrite; (2) Fe(III): Feammox enrichment was inoculated in the $20 \mathrm{ml}$ of ferrihydritecontaining basal medium amended without ${ }^{15} \mathrm{NH}_{4} \mathrm{Cl}$; and (3) $\mathrm{Fe}(\mathrm{III})+\mathrm{NH}_{4}{ }^{+}$: Feammox enrichment was inoculated in the $20 \mathrm{ml}$ of basal medium amended with both ferrihydrite and ${ }^{15} \mathrm{NH}_{4} \mathrm{Cl}$. The final concentrations of ${ }^{15} \mathrm{NH}_{4} \mathrm{Cl}$ and ferrihydrite were 0.5 and $4 \mathrm{mmol} \mathrm{L}^{-1}$ in the treatments, respectively. The number of serum vials for each treatment was 4,4 , and 24 , respectively. All the treatments were incubated at $30^{\circ} \mathrm{C}$ in a dark under anaerobic condition.

\section{Chemical Analysis}

Ferrous iron and total iron were determined as described previously (Kappler et al., 2005). Briefly, Fe(II) was determined by anaerobically transferring $100 \mu \mathrm{l}$ of culture suspension with a syringe into $900 \mu \mathrm{l}$ of $40 \mathrm{mmol} \mathrm{L}^{-1}$ sulfamic acid and incubating for $1 \mathrm{~h}$ at room temperature. Total Fe was extracted using a mixture of $20 \mathrm{mmol} \mathrm{L}^{-1}$ hydroxylamine hydrochloride and $20 \mathrm{mmol} \mathrm{L}^{-1}$ sulfamic acid (v:v = 1:1) (Klueglein et al., 2015). A 100- $\mu$ l extract was then added with $1 \mathrm{ml}$ ferrozine solution ( $1 \mathrm{~g}$ ferrozine in $50 \mathrm{mmol} \mathrm{L}^{-1}$ HEPES buffer, $\mathrm{pH} 7$ ) to generate the ferrous complex, which was quantified at $562 \mathrm{~nm}$ $\mathrm{UV} / \mathrm{Vis}$ spectrometer. Change in $\mathrm{Fe}(\mathrm{II})$ concentrations between two given time points (23 days) were used to calculate iron(III) reduction rates. 
For the ${ }^{15} \mathrm{~N}-\mathrm{N}_{2}$ analysis, vials were shaken vigorously to equilibrate the dissolved phase with gaseous phase, and $1 \mathrm{ml}$ of gas samples was collected from the headspace using gastight syringes and then injected into 12-ml glass vials (Exetainer; Labco, Lampeter, United Kingdom). The gas samples were taken on days $1,4,8,10,12,14,18$, and 22 , respectively. ${ }^{30} \mathrm{~N}_{2}$ and ${ }^{29} \mathrm{~N}_{2}$ concentrations were calculated by multiplying the moles of total $\mathrm{N}_{2}$ in the headspace by the ${ }^{30} \mathrm{~N}_{2}$ and ${ }^{29} \mathrm{~N}_{2}$ mole fractions (Zhou et al., 2016). The total $\mathrm{N}_{2}$ and $\mathrm{N}_{2} \mathrm{O}$ concentration in the headspace was measured using a robotized system coupled to a gas chromatograph (Agilent Technologies, Santa Clara, CA, United States) as previously described (Zhou et al., 2016). The mole fractions of ${ }^{30} \mathrm{~N}_{2}$ and ${ }^{29} \mathrm{~N}_{2}$ were determined by isotope ratio mass spectrometry (IRMS; Thermo Finnigan Delta V Advantage, Bremen, Germany) coupled with Gasbench II, respectively (Zhou et al., 2016). After gas collection, the remaining cultures were immediately centrifuged at $14,000 \times g$ for $15 \mathrm{~min}$ and the pellets were used for DNA extraction. The resulting supernatant was filtered through $0.22-\mu \mathrm{m}$ filters and then subjected to measurement of $\mathrm{NH}_{4}{ }^{+}, \mathrm{NO}_{2}{ }^{-}$, and $\mathrm{NO}_{3}{ }^{-}$concentrations by ion chromatography (Dionex ICS-3000 system; Diones, Sunnyvale, CA, United States). All the liquid was sampled in the anaerobic glovebox (Shel Lab Bactron IV; Shel Lab, Cornelius, OR, United States) to avoid chemical oxidation. $\mathrm{pH}$ was analyzed using a dual-channel $\mathrm{pH}$-ion-conductivitydissolved oxygenmeter (X60; Thermo Fisher Scientific, Carlsbad, CA, United States) in the anaerobic glovebox.

\section{DNA Extraction and Illumina Sequencing}

DNA was extracted using FastDNA Spin Kit (MP Biomedical, Illkirch-Graffenstaden, France) according to the manufacturer's protocol and stored at $-20^{\circ} \mathrm{C}$ for the molecular analyses. Since the biomass in the treatments amended with only $\mathrm{Fe}$ (III) or $\mathrm{NH}_{4}{ }^{+}$was extremely low, there was enough DNA extracted from these treatments.

To investigate the bacterial community structures and compositions, the V4-V5 region of bacterial was amplified using the DNA extracted from the samples in the treatment of $\mathrm{Fe}(\mathrm{III})+\mathrm{NH}_{4}{ }^{+}$as template. The amplicons were purified, quantified, pooled, and then sequenced on an Illumina Miseq PE 250 platform (Novogene, Beijing, China) (Zhou et al., 2016). The forward primer was 515F (5'-GTGCCAGCMGCCGCGG$\left.3^{\prime}\right)$, and the reverse primer consisted of a 6-bp barcode and 907R (5'-CCGTCAATTCMTTTRAGTTT-3') (Ren et al., 2014). Quantitative Insights into Microbial Ecology toolkit-version 1.9.0 (QIIME) was used to process and analyze sequences as previously described ( $\mathrm{Su}$ et al., 2015). After removal of low-quality or ambiguous reads, operational taxonomic units (OTU) were determined at 97\% similarity level using UCLUST clustering in accordance with the online instruction of QIIME for open-reference OTU pick, definition, and determination (Wang et al., 2007). The representative sequences of each OTU were assigned to taxonomy using an RDP classifier (Version 11). ${ }^{1}$

\footnotetext{
${ }^{1}$ http://rdp.cme.msu.edu
}

\section{Quantitative PCR}

The abundance of relevant genes and microbial organisms, including bacterial 16S rRNA gene, Geobacteraceae spp., Acidimicrobiaceae spp. (the reported potential microbe responsible for Feammox) (Huang and Jaffé, 2014), hzsB (hydrazine synthase), nirS (nitrite reductase), and nos $Z$ (nitrous oxide reductase) was analyzed with a real-time PCR Detection System (Roche 480; Roche, Indianapolis, IN, United States). The primer sets and thermal cycles were detailed in Supplementary Table 2. The $20-\mu$ l qPCR reaction contained $10 \mu 12 \times$ TransStart $^{\circledR}$ Top Green qPCR SuperMix (AQ131; Transgen Biotech, Beijing, China), $0.25 \mu \mathrm{M}$ each primer, $0.8 \mu \mathrm{l}$ bovine serum albumin (BSA, $20 \mathrm{mg} \mathrm{ml}^{-1}$ ), and $2 \mu \mathrm{l}$ of fivefold diluted DNA as a template. The standard curve was obtained using 10-fold serial dilutions of plasmid DNA with targetgenes. Three non-template controls were carried out for each quantitative assay. A melting curve for each reaction showed that only one special peak was detected. Only the reactions with efficiencies between 90 and 110\%, and standard curves with correlation coefficient above 0.99 were employed in this study.

\section{Statistical Analyses}

Analysis of variance (ANOVA) and Pearson correlation analysis were conducted by SPSS 18.0 (SPSS Inc., Chicago, IL, United States) and Origin 9.0 (OriginLab, Northampton, MA, United States). Statistical significance was performed using Duncan's multiple range test and denoted at $p<0.05$. The differences of the bacterial communities were analyzed by nonmetric multidimensional scaling (NMDS) based on weighted UniFrac dissimilarity among samples, which was represented by the ordination axes (Tunney et al., 2013).

\section{Data Accessibility}

The 16S rRNA gene sequences have been deposited in GenBank with accession number SRP116169.

\section{RESULTS}

\section{Iron(III) Reduction and Changes of $\mathbf{N}$ Species in the Enrichment}

In the $\mathrm{Fe}(\mathrm{III})+\mathrm{NH}_{4}{ }^{+}$treatment, $\mathrm{Fe}(\mathrm{II})$ increased up to $1.83 \pm 0.010 \mathrm{mmol} \mathrm{L}^{-1}$ after 22-day anaerobic incubation (Figure 1A). In comparison, iron(III) reduction was not detected in the treatments only amended with $\mathrm{Fe}(\mathrm{III})$ or $\mathrm{NH}_{4}{ }^{+}$after the 22-day incubation (Figure 1A).

Significant $(p<0.05)$ accumulation of ${ }^{30} \mathrm{~N}_{2}$ was detected in the $\mathrm{Fe}(\mathrm{III})+\mathrm{NH}_{4}{ }^{+}$treatment $\left(0.36 \mu \mathrm{mol} \mathrm{L}{ }^{-1}\right)$ compared to that in the treatment of $\mathrm{Fe}$ (III) $\left(0.064 \mu \mathrm{mol} \mathrm{\textrm {L } ^ { - 1 }}\right)$ or $\mathrm{NH}_{4}{ }^{+}\left(0.080 \mu \mathrm{mol} \mathrm{L}{ }^{-1}\right)$ during the incubation (Figure 1B and Supplementary Figure 1). The ${ }^{29} \mathrm{~N}_{2}$ production rates showed similar trends to that of ${ }^{30} \mathrm{~N}_{2}$ (Figure 1B and Supplementary Figure 1). Headspace $\mathrm{N}_{2} \mathrm{O}$ exhibited a higher concentration in the treatment of $\mathrm{Fe}(\mathrm{III})+\mathrm{NH}_{4}{ }^{+}\left(2.89 \times 10^{-3} \mu \mathrm{mol} \mathrm{L}^{-1}\right)$ than that in the treatment of $\mathrm{Fe}(\mathrm{III})\left(8.00 \times 10^{-4} \mu \mathrm{mol} \mathrm{L}{ }^{-1}\right)$ or $\mathrm{NH}_{4}{ }^{+}$ 


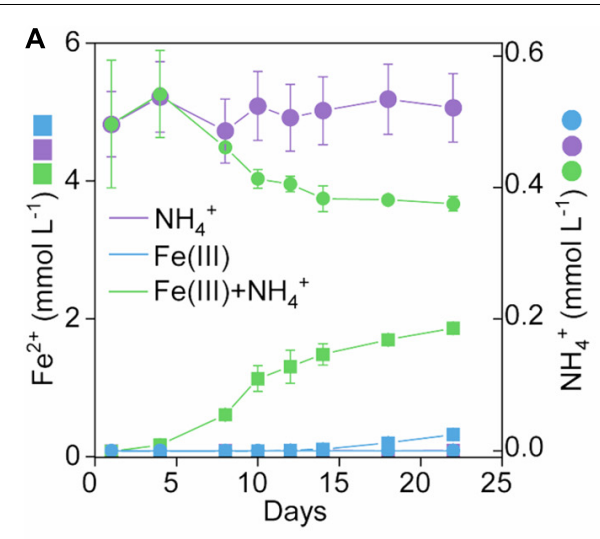

D

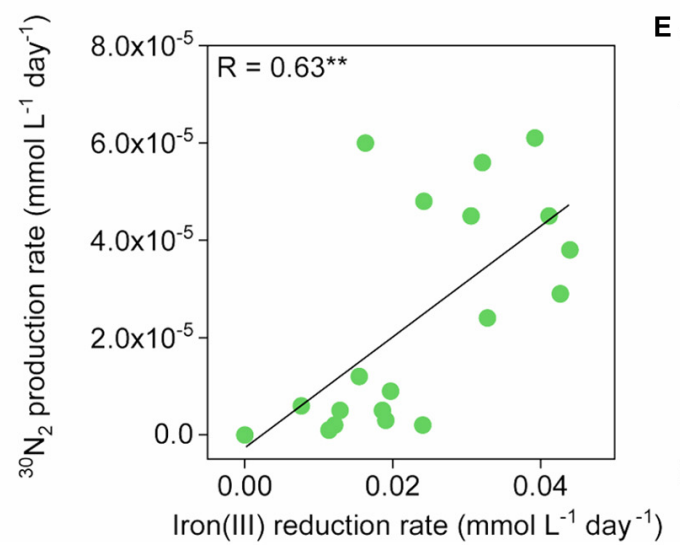

B $4 \longdiv { \mathrm { NH } _ { 4 } + }$

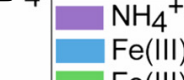

3. $\mathrm{Fe}(\mathrm{III})+\mathrm{NH}_{4}^{+}$

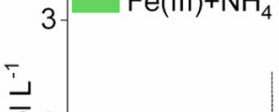

$\overline{\overline{\mathrm{g}}}^{2}$

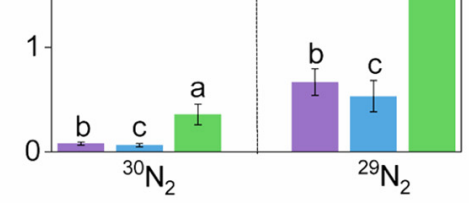

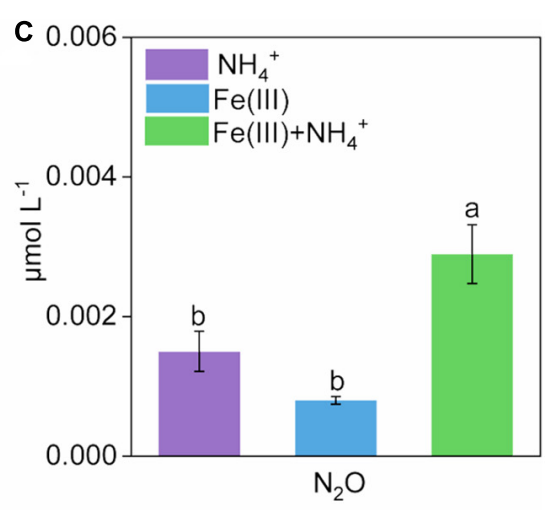

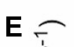

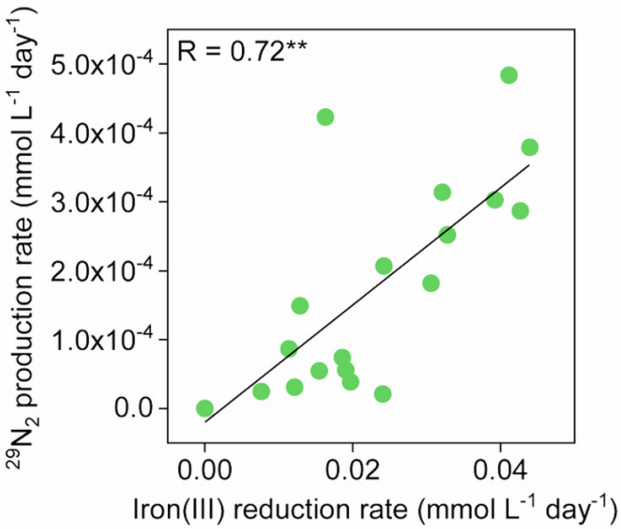

FIGURE 1 | Development of $\mathrm{Fe}(\mathrm{II}), \mathrm{NH}_{4}{ }^{+}$and $\mathrm{N}_{2}$ production in treatments during 22-day incubation. Kinetics of Fe(II) (A), $\mathrm{NH}_{4}{ }^{+}$(B), and $\mathrm{N}_{2}$ (C) production in treatments of $\mathrm{NH}_{4}{ }^{+}, \mathrm{Fe}(\mathrm{III})$, and $\mathrm{Fe}(\mathrm{III})+\mathrm{NH}_{4}{ }^{+}$during 22-day incubation. Error bars represent standard deviations of three replications. The different lowercase letters above the error bar denote statistically significant $(p<0.05)$ differences among different treatments. (D,E) The correlation between rates of iron(III) reduction and

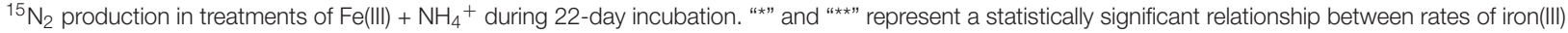
reduction and ${ }^{15} \mathrm{~N}_{2}$ production, which is denoted at $p<0.05$ and $p<0.01$, respectively.

$\left(9.01 \times 10^{-4} \mu \mathrm{mol} \mathrm{L}^{-1}\right)$ during the incubation (Figure 1C). An amount of $0.12 \mathrm{mmol} \mathrm{L}^{-1} \mathrm{NH}_{4}{ }^{+}$was consumed in the treatment of $\mathrm{Fe}(\mathrm{III})+\mathrm{NH}_{4}{ }^{+}$(Figure 1A). Almost no utilization of $\mathrm{NH}_{4}{ }^{+}$ was observed in the $\mathrm{NH}_{4}{ }^{+}$treatment (Figure 1A).

The rates of ${ }^{30} \mathrm{~N}_{2}$ and ${ }^{29} \mathrm{~N}_{2}$ production were significantly $(p<0.001)$ correlated with iron(III) reduction rates in the $\mathrm{Fe}(\mathrm{III})+\mathrm{NH}_{4}{ }^{+}$treatment (Figures 1D,E).

\section{Changes in Abundances of Bacteria and the N Cycling-Relevant Genes}

$16 \mathrm{~S}$ rRNA gene copy number increased up to $2.36 \times 10^{10}$ copies $\mathrm{L}^{-1}$ medium after incubation in the $\mathrm{Fe}(\mathrm{III})+\mathrm{NH}_{4}+$ treatment (Figure 2A). Also, the abundances of $h z s B$, nirs, and nos $Z$ rapidly elevated in the treatment of $\mathrm{Fe}(\mathrm{III})+\mathrm{NH}_{4}{ }^{+}$after 12 days (Figure 2 and Supplementary Figure 2). Especially, the gene copy numbers were higher for the genes nirS $\left(1.26 \times 10^{7}\right)$ and nos $Z\left(2.62 \times 10^{7}\right)$ than that for the gene $h z s B\left(7.36 \times 10^{6}\right.$ copies $\mathrm{L}^{-1}$ medium $)$ in the treatment of $\mathrm{Fe}(\mathrm{III})+\mathrm{NH}_{4}+$ (Figure 2A).

The abundance of Geobacteraceae spp. was about $2.03 \times 10^{6}$ copies $\mathrm{L}^{-1}$ medium after 22-day incubation in the treatment of $\mathrm{Fe}(\mathrm{III})+\mathrm{NH}_{4}{ }^{+}$(Figure 2B). By contrast,
Acidimicrobiaceae spp. kept constantly low abundance throughout the incubation (Figure 2B).

\section{Shift of Bacterial Community Composition}

In the initial inoculant, $42.94 \%$ of the total bacterial community were affiliated to the family of Ignavibacteriaceae, followed by unclassified Anaerolineae (23.68\%) and unclassified Chlorobi $(8.02 \%)$ (Figure 3). While in the treatment of $\mathrm{Fe}(\mathrm{III})+\mathrm{NH}_{4}{ }^{+}$, Geobacteraceae was the family with the highest relative abundance, followed by Comamonadaceae, Pelobacteraceae, and Pseudomonadaceae (Figure 3). These four families occupied up to $96.13 \%$ of the total microbial community (Figure 3 ).

\section{Shift in the Relative Abundances of Iron(III)-Reducers and Anammox Bacteria}

The detected iron(III) reducers included Geobacter, Pseudomonas, Clostridium, Bacillus, Thiobacillus, unclassified Geobacteraceae, Desulfotomaculum, Desulfovibrio, Desulfobulbus, and Pelobacter in the treatment of $\mathrm{Fe}(\mathrm{III})+\mathrm{NH}_{4}{ }^{+}$(Figure 4A). In comparison with the initial inoculant, the genera of Geobacter, 


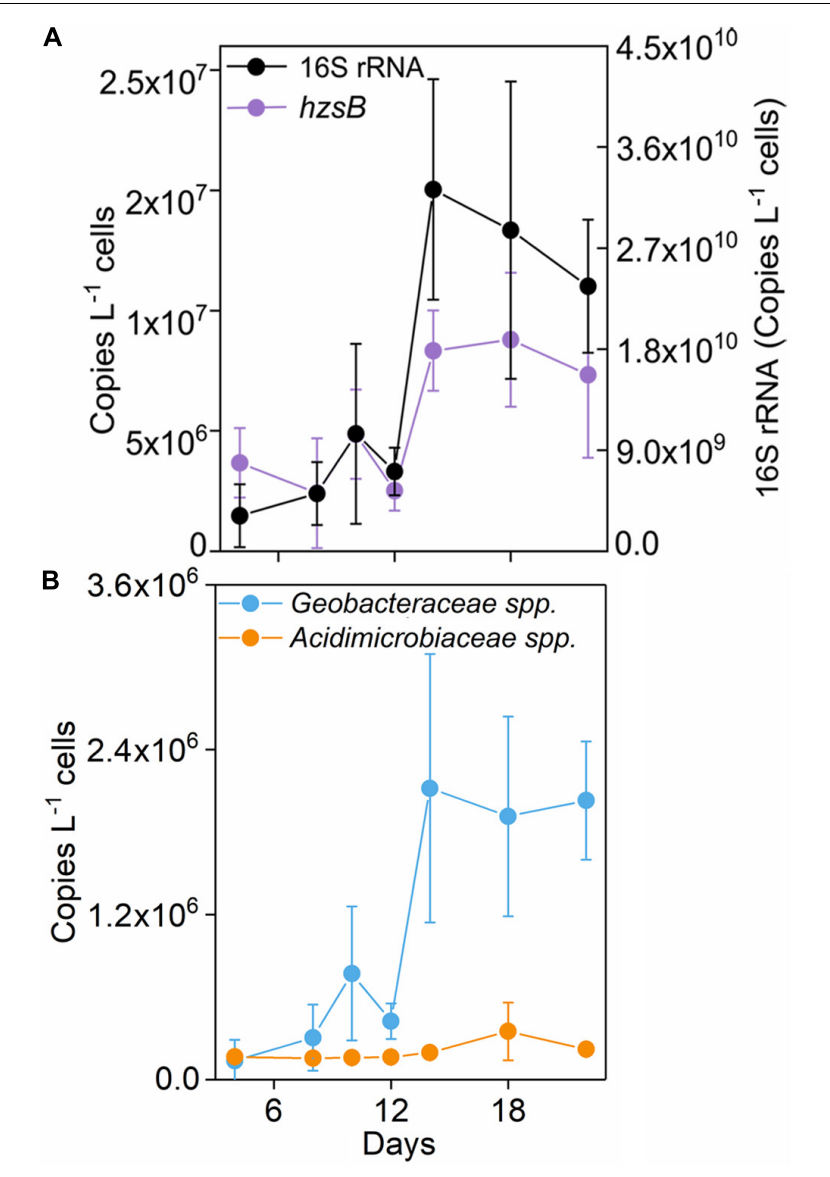

FIGURE 2 | Copy numbers of 16S rRNA gene, and nosZ (A), Geobacteraceae spp., and Acidimicrobiaceae spp. (B) in the treatment of $\mathrm{Fe}(\mathrm{III})+\mathrm{NH}_{4}+$ during 22-day incubation. Error bars represent standard deviations of three replication.

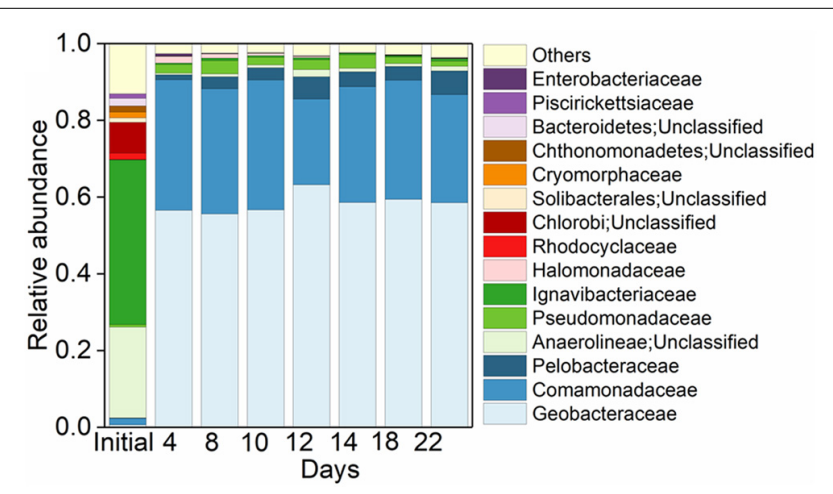

FIGURE 3 | Pattern of microbial community in treatments. Top 15 taxa at family level in the initial Anammox inoculant and the Anammox inoculant-based treatment of $\mathrm{Fe}(\mathrm{III})+\mathrm{NH}_{4}+$ during the 22-day incubation.

Pseudomonas, Clostridium, Desulfovibrio, Desulfotomaculum, and Pelobacter were significantly enriched, while the relative abundance of Bacillus and Thiobacillus decreased in the treatment of $\mathrm{Fe}(\mathrm{III})+\mathrm{NH}_{4}{ }^{+}$during the incubation (Figure 4A). Of all the iron(III) reducers, the change in relative abundances of Geobacter and unclassified Geobacteraceae were significantly $(p<0.05)$ correlated with the ${ }^{30} \mathrm{~N}_{2}$ and ${ }^{29} \mathrm{~N}_{2}$ production rates in the treatment of $\mathrm{Fe}(\mathrm{III})+\mathrm{NH}_{4}{ }^{+}$(Figure 4B).

The Anammox-relevant Planctomycetes remained with low relative abundances in the treatment of $\mathrm{Fe}(\mathrm{III})+\mathrm{NH}_{4}{ }^{+}$ after 22-day incubation. Dynamics of relative abundances of Anammox-relevant taxa, including unclassified Brocadiaceae, Brocadia, Kuenenia, and Jettenia, displayed a similar pattern in the treatment of $\mathrm{Fe}(\mathrm{III})+\mathrm{NH}_{4}{ }^{+}$. These relative abundances of Anammox bacteria reached a peak on days 10-12 and then decreased during the incubation (Figure 4C). The relative abundances of these Anammox bacteria significantly $(p<0.05)$ correlated with the rates of ${ }^{30} \mathrm{~N}_{2}$ and ${ }^{29} \mathrm{~N}_{2}$ production (Figure 4D).

\section{DISCUSSION}

Feammox is a recently identified pathway of dinitrogen generation, expecting to be applied to remove nitrogen from a wastewater treatment system. In this study, we aimed to verify the occurrence of Feammox and investigate the Feammoxassociated microbes in the sludge of a wastewater treatment system. Detection of ${ }^{15} \mathrm{~N}_{2}$ production from sludge amended with iron(III) indicated the existence of Feammox in the incubation. Anammox bacteria such as Brocadiaceae, Kuenenia, and Jettenia and iron(III) reducers including Geobacter and unclassified Geobacteraceae were found potentially involved in the Feammox process.

The Feammox incubation was established using the sludge as inoculant, which was subjected to three generations with freshly prepared medium under anaerobic condition. As a result, the major electron acceptor for anaerobic oxidation of ${ }^{15} \mathrm{~N}_{-} \mathrm{NH}_{4}{ }^{+}$was ferrihydrite during the incubation. Previous reports suggested that Anammox can be linked to the microbial reduction of natural organic matters (Rios-Del Toro et al., 2018), likely originating from the breakdown of dead biomass, for example, carbohydrate residues including cellulose and lignin (Siemann et al., 2012). The transformation between oxidized and reduced state enables the quinone group-abundant organic matters serving as electron shuttles to mediate anaerobic oxidation of ammonium to $\mathrm{N}_{2}$ (Westereng et al., 2015; RiosDel Toro et al., 2018). However, the standard Gibbs free energy released from this process $\left(\mathrm{NH}_{4}{ }^{+}+1.5\right.$ quinone- $\mathrm{NOM}_{\mathrm{ox}}$ $\rightarrow 0.5 \mathrm{~N}_{2}+1.5$ quinone $\mathrm{H}_{2}-\mathrm{NOM}_{\text {red }}+4 \mathrm{H}^{+}$) ranged from $5.8 \mathrm{~kJ} \mathrm{~mol}^{-1}$ to $-124.6 \mathrm{~kJ} \mathrm{~mol}^{-1}$ (Rios-Del Toro et al., 2018), greatly lower than that produced from the Feammox process $\left[3 \mathrm{Fe}(\mathrm{OH})_{3}+5 \mathrm{H}^{+}+\mathrm{NH}_{4}^{+} \rightarrow 3 \mathrm{Fe}^{2+}+9 \mathrm{H}_{2} \mathrm{O}+0.5 \mathrm{~N}_{2}\right.$, $\Delta_{\mathrm{r}} \mathrm{G}_{\mathrm{m}}=-245 \mathrm{~kJ} \mathrm{~mol}^{-1} ; 6 \mathrm{Fe}(\mathrm{OH})_{3}+10 \mathrm{H}^{+}+\mathrm{NH}_{4}{ }^{+}$ $\rightarrow 6 \mathrm{Fe}^{2+}+16 \mathrm{H}_{2} \mathrm{O}+\mathrm{NO}_{2}^{-}, \Delta_{\mathrm{r}} \mathrm{G}_{\mathrm{m}}=-164 \mathrm{~kJ} \mathrm{~mol}^{-1}$; $8 \mathrm{Fe}(\mathrm{OH})_{3}+14 \mathrm{H}^{+}+\mathrm{NH}_{4}^{+} \rightarrow 8 \mathrm{Fe}^{2+}+21 \mathrm{H}_{2} \mathrm{O}+\mathrm{NO}_{3}{ }^{-}$, $\Delta_{\mathrm{r}} \mathrm{G}_{\mathrm{m}}=-207 \mathrm{~kJ} \mathrm{~mol}^{-1}$ ] (Yang et al., 2012). Therefore, Anammox was probably coupled to ferrihydrite reduction during the incubation. The significant accumulation of ${ }^{30} \mathrm{~N}_{2}$ provided a solid evidence for the occurrence of Feammox in the treatment 

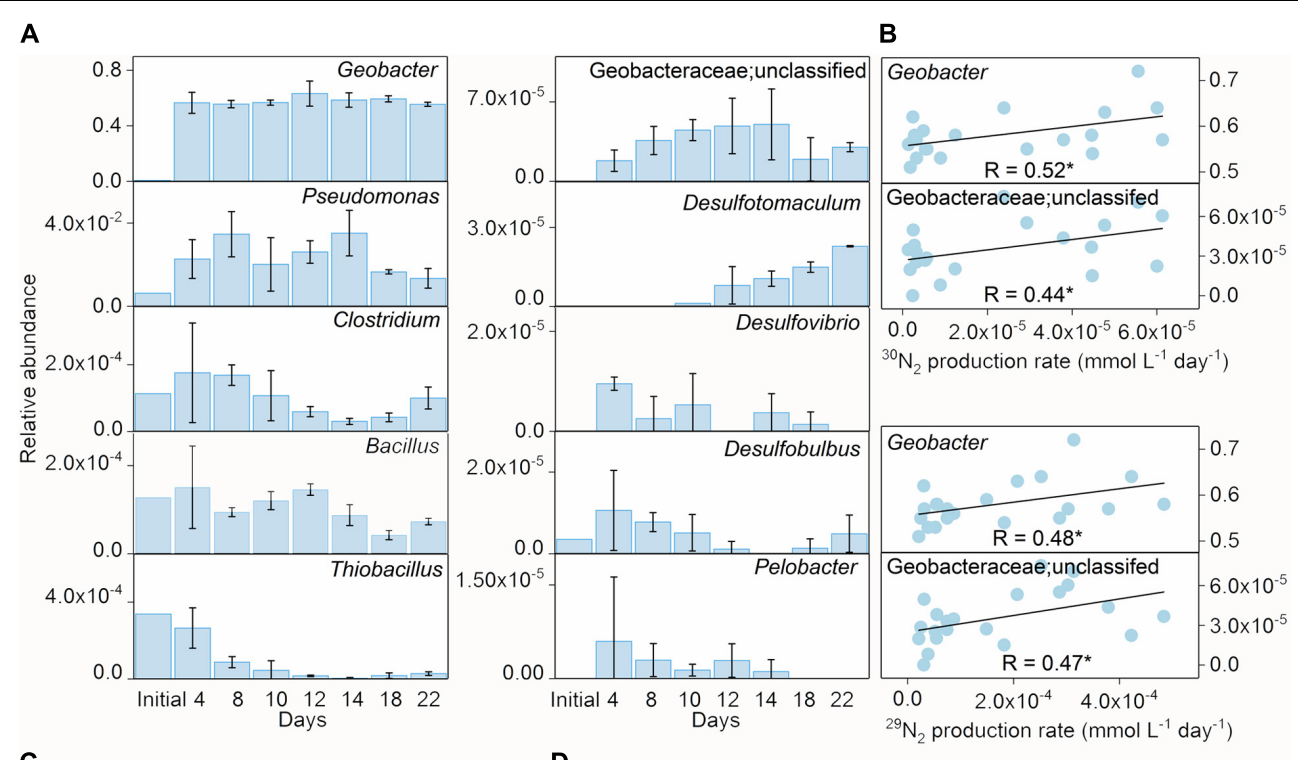

C

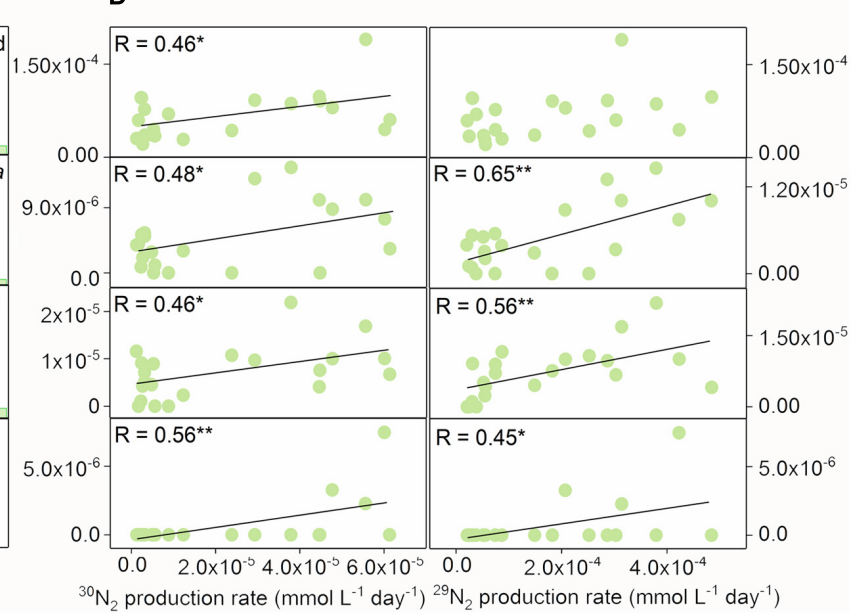

FIGURE 4 | The relative abundances of iron(III) reducers and Anammox bacteria during incubation. The relative abundances of iron(III) reducers (A) and the correlation between the relative abundances of Geobacter/unclassified Geobacteraceae and ${ }^{15} \mathrm{~N}_{2}$ production rates (B) in the inoculant-based treatment of $\mathrm{Fe}(\mathrm{III})+\mathrm{NH}_{4}+$ during 22-day incubation. Error bars represent standard deviations of three replications. The relative abundances of Brocadiaceae (unclassified), Brocadia, Kuenenia, and Jettenia (C), and the correlation between the relative abundance of Geobacter and ${ }^{15} \mathrm{~N}_{2}$ production rates (D) in the inoculant-based treatment of $\mathrm{Fe}(\mathrm{III})+\mathrm{NH}_{4}{ }^{+}$. Error bars represent standard deviations of three replication. "*” and "**” represent a statistically significant relationship between relative abundances of iron(III) reducers, Anammox bacteria, and ${ }^{15} \mathrm{~N}_{2}$ production, which is denoted at $p<0.05$ and $p<0.01$, respectively.

of $\mathrm{Fe}(\mathrm{III})+\mathrm{NH}_{4}{ }^{+}$. Codenitrification is another potential source of ${ }^{30} \mathrm{~N}_{2}$ (Laughlin and Stevens, 2002). However, it can be ruled out in this study because other ${ }^{15} \mathrm{~N}$-labeled nitrogen compounds (e.g., hydrazine and amino compounds) that could reduce ${ }^{15} \mathrm{NO}_{2}{ }^{-}$and ${ }^{15} \mathrm{NO}_{3}{ }^{-}$to $\mathrm{N}_{2}$ were not available in the culture. Under these conditions, direct $\mathrm{N}_{2}$ production from Feammox, or Feammox-produced $\mathrm{NO}_{2}{ }^{-}$or $\mathrm{NO}_{3}{ }^{-}$followed by denitrification or Anammox are the possible pathways for ${ }^{30} \mathrm{~N}_{2}$ generation, supporting the occurrence of Feammox in the treatment of $\mathrm{Fe}(\mathrm{III})+\mathrm{NH}_{4}{ }^{+}$. The positive correlation $(p<0.0001$; Figures 1D,E) between $\mathrm{Fe}(\mathrm{III})$ reduction and ${ }^{30} \mathrm{~N}_{2} /{ }^{29} \mathrm{~N}_{2}$ production rates further verified the existence of Feammox in the treatment of $\mathrm{Fe}(\mathrm{III})+\mathrm{NH}_{4}{ }^{+}$during the anoxic incubation.
The amount of ${ }^{15} \mathrm{~N}_{2}, \mathrm{~N}_{2} \mathrm{O}$, and ${ }^{15} \mathrm{NO}_{\mathrm{x}}{ }^{-}\left(3.63 \mu \mathrm{mol} \mathrm{L}{ }^{-1}\right.$; Supplementary Table 3 ) produced from the treatment of $\mathrm{Fe}(\mathrm{III})+\mathrm{NH}_{4}{ }^{+}$was far less than that of $\mathrm{NH}_{4}{ }^{+}$depleted during the incubation, indicating that the majority of $\mathrm{NH}_{4}^{+}$was assimilated into microbial biomass (Tupas and Koike, 1990). The abundant genera such as Pseudomonas and Bacillus detected in this study, which are able to assimilate ammonia during their growth (Kim and Hollocher, 1982; Kanamori et al., 1989), may be the major $\mathrm{NH}_{4}{ }^{+}$consumers in the treatment of $\mathrm{Fe}(\mathrm{III})+\mathrm{NH}_{4}{ }^{+}$.

The molar ratio of reduced $\mathrm{Fe}$ (III) to the total $\mathrm{NH}_{4}{ }^{+}$ oxidation was about 15.41 in the $\mathrm{Fe}(\mathrm{III})+\mathrm{NH}_{4}{ }^{+}$treatment (Figure 1), which did not match the stoichiometry (ranging from 3 to 8 ) in the three Feammox equations (Yang et al., 2012; Ding et al., 2014; Zhou et al., 2016). This suggested that only 

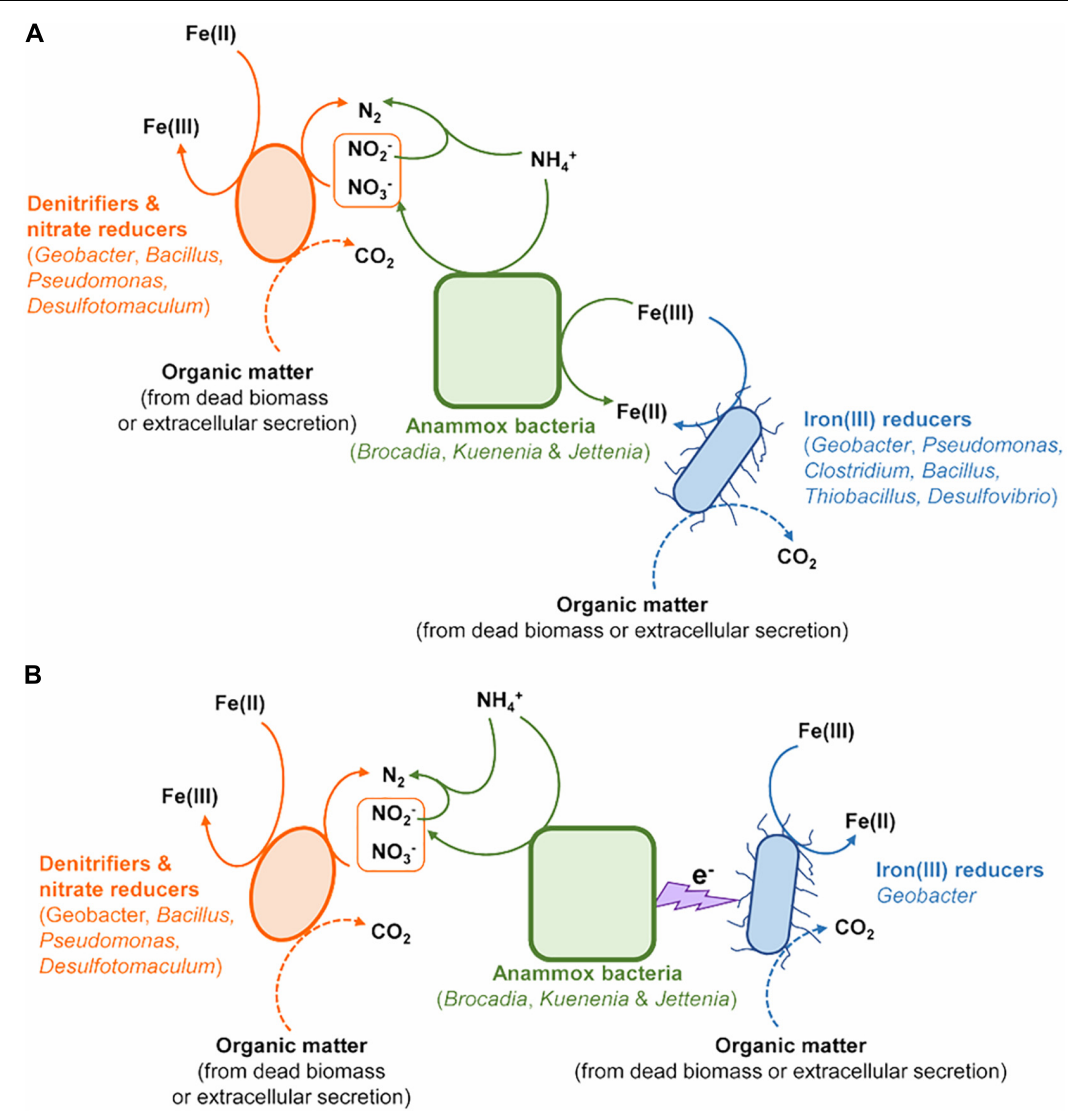

FIGURE 5 | The potential models of microorganisms contributing to N removal via Feammox. (A) Anammox bacteria directly involved in the Feammox-associated $\mathrm{N}$ removal. (B) Interaction between Anammox bacteria and Geobacter linked to Feammox-associated $\mathrm{N}$ removal.

a minor fraction of reduced $\mathrm{Fe}(\mathrm{III})$ was linked to the $\mathrm{NH}_{4}{ }^{+}$ oxidation in the $\mathrm{Fe}(\mathrm{III})+\mathrm{NH}_{4}{ }^{+}$treatment. According to the thermodynamic calculations, the amount of iron reduction associated with Feammox was $0.36-0.96 \mathrm{mmol} \mathrm{L}^{-1}$, accounting for $19.67-52.46 \%$ of total $\mathrm{Fe}$ (III) reduction in the treatment of $\mathrm{Fe}(\mathrm{III})+\mathrm{NH}_{4}{ }^{+}$. Thus, a majority of the reduced $\mathrm{Fe}$ (III) was linked to the oxidation of other substrates mediated by microorganisms. Because exogenous organic matter was not added in the treatment of $\mathrm{Fe}(\mathrm{III})+\mathrm{NH}_{4}{ }^{+}$, the substrates might be organic compounds sourced from the dead biomass or extracellular secretion from the microbes. Among all the iron(III)-reducing bacteria, the family of Geobacteraceae was abundant in the treatment of $\mathrm{Fe}$ (III) $+\mathrm{NH}_{4}{ }^{+}$(Figure 3). The genus of Geobacter is able to reduce Fe(III) associated with organic substrate oxidation to support its growth (Lovley, 1991). The relative abundance of Geobacteraceae showed an increase on days 10 and 12, which was in agreement with the rapidly increasing copy number of Geobacter after 12-day incubation in the treatment of $\mathrm{Fe}(\mathrm{III})+\mathrm{NH}_{4}{ }^{+}$(Figures 2B, 3, 4A), indicating Geobacter was the dominant genus in Geobacteraceae. The positive correlation between the abundance of Geobacter and accumulation of ${ }^{15} \mathrm{~N}_{2}$ in the treatment of $\mathrm{Fe}(\mathrm{III})+\mathrm{NH}_{4}{ }^{+}$ (Figure 4B) suggested that Geobacter may exert a potential role in Feammox.
The abundance of Anammox bacteria, including Brocadiaceae, Kuenenia, and Jettenia, showed significant correlation with ${ }^{15} \mathrm{~N}_{2}$ production in the treatment of $\mathrm{Fe}(\mathrm{III})+\mathrm{NH}_{4}{ }^{+}$(Figure 4D), suggesting Anammox bacteria were linked with Feammox during the incubation. Although the mechanism about the role of Anammox bacteria as Feammox players was still unknown, a variety of reports have shown their versatile metabolism. Firstly, Anammox bacteria are capable of anaerobically oxidizing ammonium via anammoxosome coupled with other electron acceptors such as sulfate in addition to nitrite (Liu et al., 2008; Rikmann et al., 2014). The $\Delta \mathrm{G}_{\mathrm{o}}$ of sulfate-reducing anaerobic ammonium oxidation proceeded by Anammox species Anammoxoglobus sulfate $\left(2 \mathrm{NH}_{4}{ }^{+}+\mathrm{SO}_{4}{ }^{2-}\right.$ $\rightarrow \mathrm{S}_{\mathrm{o}}+\mathrm{N}_{2}+4 \mathrm{H}_{2} \mathrm{O} \Delta \mathrm{G}_{\mathrm{o}}=-46 \mathrm{~kJ} \mathrm{~mol}^{-1} ; 8 \mathrm{NH}_{4}{ }^{+}+3 \mathrm{SO}_{4}{ }^{2-} \rightarrow$ $\left.\mathrm{HS}^{-}+4 \mathrm{~N}_{2}+12 \mathrm{H}_{2} \mathrm{O}+5 \mathrm{H}^{+} \Delta \mathrm{G}_{\mathrm{o}}=-22 \mathrm{~kJ} \mathrm{~mol}^{-1}\right)$ is obviously lower than that of Feammox (Liu et al., 2008; Rikmann et al., 2014), suggesting that Anammox bacteria in the enrichment should favor Feammox. Secondly, genera of Brocadia and Kuenenia have iron(III)-reducing ability using organic matter (e.g., formate, acetate, and propionate) as electron donor (Graaf et al., 1996; Zhao et al., 2014); 80\% of the ferric iron reductase in these Anammox bacteria locates in the membrane fraction and part of them termed as dissimilatory ferric iron reductases are the essential terminal reductase of the $\mathrm{Fe}(\mathrm{III})$ respiratory 
pathway in iron(III)-reducing bacteria (Schröder et al., 2003; Zhao et al., 2014). It provided a cue that the Anammox bacteria detected in our study, including Brocadiaceae, Kuenenia, and Jettenia, were capable of reducing iron(III) linked to oxidizing ammonium anaerobically at same time. Moreover, several publications demonstrated the potential role of Anammox bacteria in Feammox based on the increase in the $\mathrm{N}_{2}$ production after amendment with iron(III) oxides in the Anammox sludge (Chen et al., 2014; Wang et al., 2016; Li H. et al., 2018; Li X. et al., 2018; Yin et al., 2019). The Feammox bacteria Acidimicrobiaceae sp. were previously identified in acid soil with $\mathrm{pH}$ between 3.5 and 4.5 (Huang and Jaffé, 2014); however, the gene copy of the Acidimicrobiaceae spp. was extremely low (Figure 2B), and members of this family were not detected via Illumina sequencing in this study, which might indicate that this reported family made very little contribution to Feammox-linked $\mathrm{N}_{2}$ production under neutral condition. In addition, the aerobic ammonium-oxidizing bacteria Nitrosomonas spp. were found to be highly enriched in the ammonium-containing anoxic condition (Lek Noophan et al., 2009), whereas they were not detected through Illumina sequencing and amoA-based qPCR (data not shown) in the treatment of $\mathrm{Fe}(\mathrm{III})+\mathrm{NH}_{4}{ }^{+}$in this study. All of these disclosed that the Anammox bacteria Brocadiaceae, Kuenenia, and Jettenia had potential for Feammox-associated anaerobic ammonium oxidation (Figure 5A).

Cooperation between Anammox bacteria and iron(III)reducers such as Geobacter could also complete the Feammox process (Figure 5B). The conductive pili of Geobacter provide the chance to extend electron transfer ability beyond the outer surface of their cells (Reguera et al., 2005). These pili offer the possibility for Geobacter to accept electrons from anaerobic ammonium oxidation by Anammox bacteria through periplasmic or outer membrane electron transfer protein (Reguera et al., 2005). The increase in the gene copy numbers of nirS, nos $Z$, $h z s B$, and relative abundances in nitrate reducers/denitrifiers (including Geobacter, Pseudomonas, Bacillus, Clostridium, and Desulfotomaculum) (Zhou et al., 2019) further indicated the contribution of denitrification, nitrate reduction, Anammox and nitrate reduction dependent iron(II) oxidation to $\mathrm{N}$ turnover in the $\mathrm{Fe}(\mathrm{III})+\mathrm{NH}_{4}{ }^{+}$treatment during the incubation (Figures 5A,B).

Potential Feammox rate was estimated with a value of $0.49 \mu \mathrm{g} \mathrm{N} \mathrm{kg}^{-1} \mathrm{~d}^{-1}$ based on the ${ }^{30} \mathrm{~N}_{2}$ production rates, which was comparable to that reported in paddy soil $(0.17-0.59 \mu \mathrm{g}$ $\mathrm{N} \mathrm{kg}^{-1} \mathrm{~d}^{-1}$ ), intertidal wetland (0.24-0.36 $\left.\mu \mathrm{g} \mathrm{N} \mathrm{kg}^{-1} \mathrm{~d}^{-1}\right)$, and tropical forest soil (about $0.32 \mathrm{mg} \mathrm{N} \mathrm{kg}^{-1} \mathrm{~d}^{-1}$ ) (Clement et al., 2005; Yang et al., 2012; Ding et al., 2014; Li et al., 2019). However, the contribution of Feammox to $\mathrm{N}$ loss was much lower than that of Anammox enrichment from the sludge $\left(4.1 \times 10^{6} \mu \mathrm{g} \mathrm{N} \mathrm{kg} \mathrm{d}^{-1}\right)$ (Chen et al., 2014), suggesting a substantially low $\mathrm{N}$ removal efficiency via Feammox. Furthermore, the minor contribution ratio of Feammox to $\mathrm{N}$ loss in this study was inconsistent with the previous reports in the Anammox sludge, which showed that $\mathrm{Fe}$ (III) addition increased the $\mathrm{N}$ removal up to $0.8 \times 10^{6} \mu \mathrm{g} \mathrm{N} \mathrm{kg} \mathrm{d}^{-1}$ (Chen et al., 2014; Wang et al., 2016). The significantly lower relative abundance of Anammox bacteria in the treatment of
$\mathrm{Fe}(\mathrm{III})+\mathrm{NH}_{4}{ }^{+}$(Figures 2A, 3, 4C) than the those reported in the previous wastewater treatment system (Chen et al., 2014; Wang et al., 2016) may be an important reason for low amount of $\mathrm{N}_{2}$ via Feammox. Firstly, limited capability of substrate utilization by Anammox bacteria led to slow growth rate and long doubling time (Jetten et al., 2005). As a result, these Anammox bacteria were overwhelmed by iron(III) reducers that could efficiently obtain energy from dissimilatory iron(III) reduction. Secondly, the relative abundances of the Brocadiaceae, Kuenenia, and Jettenia decreased in the treatment of $\mathrm{Fe}(\mathrm{III})+\mathrm{NH}_{4}{ }^{+}$ (Figure 4C), which was likely due to the accumulation of $\mathrm{NO}_{2}{ }^{-} / \mathrm{NO}_{3}{ }^{-}$after 12-day incubation (Supplementary Table 3). Iron(II) coexistence with $\mathrm{NO}_{2}^{-}$(Supplementary Figure 2), which might lead to the $\mathrm{NO}_{\mathrm{x}}{ }^{-}$dependent $\mathrm{Fe}(\mathrm{II})$ oxidation, can severely inhibit the activity of Anammox bacteria (Zhao et al., 2014). Thirdly, dilution of Anammox bacteria via three generations of subculture may be another important reason for the low activity of Feammox-associated $\mathrm{N}_{2}$ production decreased during the incubation. Besides, $\mathrm{Fe}_{3} \mathrm{O}_{4}$ can form from rapid iron(III) reduction with the production of $\mathrm{Fe}(\mathrm{II})$ absorbed on the ferric oxides surface and then improve $\mathrm{N}$ removal during Feammox process (Kappler et al., 2014; Li H. et al., 2018; Li X. et al., 2018). Hence, it can be inferred that Fe(II) was accumulated with relatively low extent after subculturing in the treatment of $\mathrm{Fe}(\mathrm{III})+\mathrm{NH}_{4}{ }^{+}$; therefore, the amount of $\mathrm{Fe}_{3} \mathrm{O}_{4}$ produced in the treatment was lower compared to the sludge reactor in continuous operation.

\section{CONCLUSION}

This study demonstrated the occurrence of Feammox in Anammox inoculant-based enrichment. The relative abundances of Geobacter and Anammox bacteria such as Brocadiaceae, Kuenenia, and Jettenia were significantly correlated with ${ }^{15} \mathrm{~N}_{2}$ production rates, indicating their potential role in Feammoxinvolved $\mathrm{N}$ removal. We proposed that sole Anammox bacteria or cooperation between Anammox bacteria and Geobacter or unclassified Geobacteraceae could complete the Feammox process during the incubation. Our results suggested the potential role of Anammox bacteria in the nitrogen removal via the Feammox process.

\section{DATA AVAILABILITY STATEMENT}

The datasets presented in this study can be found in online repositories. The names of the repository/repositories and accession number(s) can be found in the article/ Supplementary Material.

\section{AUTHOR CONTRIBUTIONS}

X-RY, HL, and G-WZ did the experiments, conceived and designed the project, and analyzed the data. J-QS gave assistance 
in lab work and laboratory analyses. X-RY wrote the manuscript. X-RY, HL, J-QS, and G-WZ revised the manuscript. All authors read and approved the final manuscript.

\section{FUNDING}

This work was supported by the National Natural Science Foundation of China (41771285 and 42021005).

\section{ACKNOWLEDGMENTS}

We thank Han Zhang (Institute of Urban Environment, Chinese Academy of Sciences) for kindly supporting the determination of $\delta^{15} \mathrm{~N}$-nitrate and $\delta^{15} \mathrm{~N}$-nitrite.

\section{REFERENCES}

Cervantes, F. J., Meza-Escalante, E. R., Texier, A. C., and Gómez, J. (2009). Kinetic limitations during the simultaneous removal of p-cresol and sulfide in a denitrifying process. J. Ind. Microbiol. Biotechnol. 36, 1417-1424. doi: 10.1007/s10295-009-0628-6

Chen, H., Yu, J. J., Jia, X. Y., and Jin, R. C. (2014). Enhancement of anammox performance by $\mathrm{Cu}(\mathrm{II}), \mathrm{Ni}(\mathrm{II})$ and $\mathrm{Fe}(\mathrm{III})$ supplementation. Chemosphere 117, 610-616. doi: 10.1016/j.chemosphere.2014.09.047

Clement, J., Shrestha, J., Ehrenfeld, J., and Jaffe, P. (2005). Ammonium oxidation coupled to dissimilatory reduction of iron under anaerobic conditions in wetland soils. Soil Biol. Biochem. 37, 2323-2328. doi: 10.1016/j.soilbio.2005.03. 027

Ding, B., Chen, Z., Li, Z., Qin, Y., and Chen, S. (2019). Nitrogen loss through anaerobic ammonium oxidation coupled to Iron reduction from ecosystem habitats in the Taihu estuary region. Sci. Total Environ. 662, 600-606. doi: 10.1016/j.scitotenv.2019.01.231

Ding, B., Li, Z., and Qin, Y. (2017). Nitrogen loss from anaerobic ammonium oxidation coupled to Iron(III) reduction in a riparian zone. Environ. Pollut. 231(Pt 1), 379-386. doi: 10.1016/j.envpol.2017.08.027

Ding, L. J., An, X. L., Li, S., Zhang, G. L., and Zhu, Y. G. (2014). Nitrogen loss through anaerobic ammonium oxidation coupled to iron reduction from paddy soils in a chronosequence. Environ. Sci. Technol. 48, 10641-10647. doi: 10.1021/ es503113s

Graaf, A. A., Bruijn, P., Robertson, L. A., Jetten, M. S. M., and Kuenen, J. G. (1996). Autotrophic growth of anaerobic ammonium-oxidizing microorganisms in a fluidized bed reactor. Microbiology 142, 2187-2196. doi: 10.1099/13500872142-8-2187

Huang, S., and Jaffé, P. R. (2014). Characterization of incubation experiments and development of an enrichment culture capable of ammonium oxidation under iron reducing conditions. Biogeosciences 11, 12295-12321. doi: 10.5194/bgd11-12295-2014

Jetten, M. S. M., Cirpus, I., Kartal, B., Niftrik, L., Pas-Schoonen, K. T., Sliekers, O., et al. (2005). 1994-2004: 10 years of research on the anaerobic oxidation of ammonium. Biochem. Soc. Trans. 33, 119-123. doi: 10.1042/BST0330119

Kanamori, K., Weiss, R. L., and Roberts, J. D. (1989). Ammonia assimilation pathways in nitrogen-fixing Clostridium kluyverii and Clostridium butyricum. J. Bacteriol. 171, 2148-2154.

Kappler, A., Schink, B., and Newman, D. K. (2005). Fe(III) mineral formation and cell encrustation by nitrate dependent $\mathrm{Fe}(\mathrm{II})$ oxidizers the nitrate dependent Fe(II) oxidizer strain BoFeN1. Geobiology 3, 235-245. doi: 10.1111/j.1472-4669. 2006.00056.x

Kappler, A., Wuestner, M. L., Ruecker, A., Harter, J., Halama, M., and Behrens, S. (2014). Biochar as an electron shuttle between bacteria and Fe(III) minerals. Environ. Sci. Technol. Lett. 1, 339-344. doi: 10.1021/ez5002209

Kim, C. H., and Hollocher, T. C. (1982). 13N isotope studies on the pathway of ammonia assimilation in Bacillus megaterium and Escherichia coli. J. Bacteriol. 151, 358-366. doi: 10.1128/JB.151.1.358-366.1982

\section{SUPPLEMENTARY MATERIAL}

The Supplementary Material for this article can be found online at: https://www.frontiersin.org/articles/10.3389/fmicb. 2021.717249/full\#supplementary-material

Supplementary Figure 1 | The dynamics of ${ }^{29} \mathrm{~N}_{2}$ and ${ }^{30} \mathrm{~N}_{2}$ production in the treatment of $\mathrm{Fe}(\mathrm{III})+\mathrm{NH}_{4}+$ during 22-day incubation.

Supplementary Figure 2 | The time course of abundances of nirS and nos $Z$, and concentrations of $\mathrm{NO}_{3}{ }^{-}$and $\mathrm{NO}_{2}{ }^{-}$in the treatment of $\mathrm{Fe}(\mathrm{III})+\mathrm{NH}_{4}{ }^{+}$during 22-day incubation.

Supplementary Table 1 | Characteristic of the initial inoculant slurry.

Supplementary Table 2 | Primers and qPCR processes used in this study.

Supplementary Table 3 | The concentrations of ${ }^{15} \mathrm{NO}_{\mathrm{x}}{ }^{-}$in the $\mathrm{Fe}(\mathrm{III})+\mathrm{NH}_{4}{ }^{+}$ treatment after 22-day incubation.

Klueglein, N., Picardal, F., Zedda, M., Zwiener, C., and Kappler, A. (2015). Oxidation of $\mathrm{Fe}(\mathrm{II})$-EDTA by nitrite and by two nitrate-reducing $\mathrm{Fe}(\mathrm{II})$ oxidizing Acidovorax strains. Geobiology 13, 198-207. doi: 10.1111/gbi.12125

Laughlin, R. J., and Stevens, R. J. (2002). Evidence for fungal dominance of denitrification and codenitrification in a grassland soil. Soil Sci. Soc. Am. J. 66, 1540-1548. doi: 10.2136/sssaj2002.1540

Lek Noophan, P., Sripiboon, S., Damrongsri, M., and Munakata-Marr, J. (2009). Anaerobic ammonium oxidation by Nitrosomonas spp. and anammox bacteria in a sequencing batch reactor. J. Environ. Manage. 90, 967-972. doi: 10.1016/j. jenvman.2008.03.003

Li, H., Chi, Z., and Yan, B. (2018). Insight into the impact of Fe3O4 nanoparticles on anammox process of subsurface-flow constructed wetlands under long-term exposure. Environ. Sci. Pollut. Res. Int. 25, 29584-29592. doi: 10.1007/s11356018-2975-1

Li, H., Su, J. Q., Yang, X. R., Zhou, G. W., Lassen, S. B., and Zhu, Y. G. (2019). RNA stable isotope probing of potential Feammox population in paddy soil. Environ. Sci. Technol. 53, 4841-4849. doi: 10.1021/acs.est.8b05016

Li, X., Hou, L., Liu, M., Zheng, Y., Yin, G., Lin, X., et al. (2015). Evidence of nitrogen loss from anaerobic ammonium oxidation coupled with ferric iron reduction in an intertidal wetland. Environ. Sci. Technol. 49, 11560-11568. doi: 10.1021/acs.est.5b03419

Li, X., Huang, Y., Liu, H. W., Wu, C., Bi, W., Yuan, Y., et al. (2018). Simultaneous $\mathrm{Fe}(\mathrm{III})$ reduction and ammonia oxidation process in Anammox sludge. J. Environ. Sci. 64, 42-50. doi: 10.1016/j.jes.2017.01.002

Liu, S., Yang, F., Gong, Z., Meng, F., Chen, H., Xue, Y., et al. (2008). Application of anaerobic ammonium-oxidizing consortium to achieve completely autotrophic ammonium and sulfate removal. Bioresour. Technol. 99, 6817-6825. doi: 10. 1016/j.biortech.2008.01.054

Lovley, D. R. (1991). Dissimilatory Fe(III) and Mn(IV) reduction. Mircrobiol. Rev. 55, 259-287. doi: 10.1016/S0065-2911(04)49005-5

Lovley, D. R., and Phillips, E. J. (1988). Novel mode of microbial energy metabolism: organic carbon oxidation coupled to dissimilatory reduction of iron or manganese. Appl. Environ. Microbiol. 54, 1472-1480.

Reguera, G., McCarthy, K. D., Mehta, T., Nicoll, J. S., Tuominen, M. T., and Lovley, D. R. (2005). Extracellular electron transfer via microbial nanowires. Nature 435, 1098-1101. doi: 10.1038/nature03661

Ren, G. D., Zhang, H. Y., Lin, X. G., Zhu, J. G., and Jia, Z. J. (2014). Response of phyllosphere bacterial communities to elevated $\mathrm{CO} 2$ during rice growing season. Appl. Microbiol. Biotechnol. 98, 9459-9471. doi: 10.1007/s00253-0145915-0

Rikmann, E., Zekker, I., Tomingas, M., Vabamae, P., Kroon, K., Saluste, A., et al. (2014). Comparison of sulfate-reducing and conventional Anammox upflow anaerobic sludge blanket reactors. J. Biosci. Bioeng. 118, 426-433. doi: 10.1016/ j.jbiosc.2014.03.012

Rios-Del Toro, E. E., and Cervantes, F. J. (2016). Coupling between anammox and autotrophic denitrification for simultaneous removal of ammonium and sulfide by enriched marine sediments. Biodegradation 27, 107-118. doi: 10 . 1007/s10532-016-9759-4 
Rios-Del Toro, E. E., Valenzuela, E. I., Ramírez, J. E., López-Lozano, N. E., and Cervantes, F. J. (2018). Anaerobic ammonium oxidation linked to microbial reduction of natural organic matter in marine sediments. Environ. Sci. Technol. Lett. 5, 571-577. doi: 10.1021/acs.estlett.8b00330

Sawayama, S. (2006). Possibility of anoxic ferric ammonium oxidation. J. Biosci. Bioeng. 101, 70-72. doi: 10.1263/jbb.101.70

Schröder, I., Johnson, E., and de Vries, S. (2003). Microbial ferric iron reductases. FEMS Microbiol. Rev. 27, 427-447. doi: 10.1016/s0168-6445(03)00043-3

Siemann, S., Caron, F., Riopel, R., and Borraro, V. (2012). Laboratory study on the impact of $\mathrm{pH}$ and salinity on the fluorescence signal of natural organic matter (NOM) relevant to groundwaters from a Canadian shield sampling site. Water Qual. Res. J. Can. 47, 131-139. doi: 10.2166/wqric.2012.028

Strous, M., Kuenen, J. G., Furerst, J. A., Wagner, M., and Jetten, M. S. M. (2002). The Anammox case e a new experimental manifesto for microbiological ecophysiology. Antonie Van Leeuwenhoek 81, 693-702. doi: 10.1023/A: 1020590413079

Su, J. Q., Wei, B., Ou-Yang, W. Y., Huang, F. Y., Zhao, Y., Xu, H. J., et al. (2015). Antibiotic resistome and its association with bacterial communities during sewage sludge composting. Environ. Sci. Technol. 49, 7356-7363. doi: 10.1021/acs.est.5b01012

Tunney, M. M., Einarsson, G. G., Wei, L., Drain, M., Klem, E. R., Cardwell, C., et al. (2013). Lung microbiota and bacterial abundance in patients with bronchiectasis when clinically stable and during exacerbation. Am. J. Respir. Cell Mol. Biol. 187, 1118-1126. doi: 10.1164/rccm.201210-1937OC

Tupas, L., and Koike, I. (1990). Amino acid and ammonium utilization by heterotrophic marine bacteria grown in enriched seawater. Limnol. Oceanogr. 35, 1145-1155. doi: 10.4319/lo.1990.35.5.1145

Wang, Q., Garrity, G. M., Tiedje, J. M., and Cole, J. R. (2007). Naive Bayesian classifier for rapid assignment of rRNA sequences into the new bacterial taxonomy. Appl. Environ. Microbiol. 73, 5261-5267. doi: 10.1128/AEM.000 62-07

Wang, X., Shu, D., and Yue, H. (2016). Taxonomical and functional microbial community dynamics in an Anammox-ASBR system under different Fe (III) supplementation. Appl. Microbiol. Biotechnol. 100, 10147-10163. doi: 10.1007/ s00253-016-7865-1

Westereng, B., Cannella, D., Wittrup Agger, J., Jorgensen, H., Larsen Andersen, M., Eijsink, V. G., et al. (2015). Enzymatic cellulose oxidation is linked to lignin by long-range electron transfer. Sci. Rep. 5:18561. doi: 10.1038/srep18561
Yang, W. H., Weber, K. A., and Silver, W. L. (2012). Nitrogen loss from soil through anaerobic ammonium oxidation coupled to iron reduction. Nat. Geosci. 5, 538-541. doi: 10.1038/ngeo1530

Yin, S., Li, J., Dong, H., and Qiang, Z. (2019). Enhanced nitrogen removal through marine anammox bacteria $(\mathrm{MAB})$ treating nitrogen-rich saline wastewater with Fe(III) addition: nitrogen shock loading and community structure. Bioresour. Technol. 287:121405. doi: 10.1016/j.biortech.2019.121405

Zhang, Z. J., Li, Y., Chen, S., Wang, S., and Bao, X. (2012). Simultaneous nitrogen and carbon removal from swine digester liquor by the Canon process and denitrification. Bioresour. Technol. 114, 84-89. doi: 10.1016/j.biortech.2012.03. 006

Zhao, R., Zhang, H., Li, Y., Jiang, T., and Yang, F. (2014). Research of iron reduction and the iron reductase localization of anammox bacteria. Curr. Microbiol. 69, 880-887. doi: 10.1007/s00284-014-0668-7

Zhou, G. W., Yang, X. R., Li, H., Marshall, C. W., Zheng, B. X., Yan, Y., et al. (2016). Electron shuttles enhance anaerobic ammonium oxidation coupled to iron(III) reduction. Environ. Sci. Technol. 50, 9298-9307. doi: 10.1021/acs.est.6b02077

Zhou, G. W., Yang, X. R., Sun, A. Q., Li, H., Lassen, S. B., Zheng, B. X., et al. (2019). Mobile incubator for iron(III) reduction in the gut of the soil-feeding earthworm Pheretima guillelmi and interaction with denitrification. Environ. Sci. Technol. 53, 4215-4223. doi: 10.1021/acs.est.8b06187

Conflict of Interest: The authors declare that the research was conducted in the absence of any commercial or financial relationships that could be construed as a potential conflict of interest.

Publisher's Note: All claims expressed in this article are solely those of the authors and do not necessarily represent those of their affiliated organizations, or those of the publisher, the editors and the reviewers. Any product that may be evaluated in this article, or claim that may be made by its manufacturer, is not guaranteed or endorsed by the publisher.

Copyright (c) 2021 Yang, Li, Su and Zhou. This is an open-access article distributed under the terms of the Creative Commons Attribution License (CC BY). The use, distribution or reproduction in other forums is permitted, provided the original author(s) and the copyright owner(s) are credited and that the original publication in this journal is cited, in accordance with accepted academic practice. No use, distribution or reproduction is permitted which does not comply with these terms. 